\title{
DEFORMATION-FREE WELDING OF STRINGER PANELS OF TITANIUM ALLOY VT20
}

\author{
B.E. PATON ${ }^{1}$, L.M. LOBANOV ${ }^{1}$, V.L. LYSAK ${ }^{1}$, V.V. KNYSH ${ }^{1}$, V.I. PAVLOVSKY ${ }^{1}$, \\ V.P. PRILUTSKY ${ }^{1}$, A.N. TIMOSHENKO ${ }^{1}$, P.V. GONCHAROV ${ }^{1}$ and GUAN QIAO ${ }^{2}$ \\ ${ }^{1}$ E.O. Paton Electric Welding Institute, NASU \\ 11 Bozhenko Str., 03680, Kiev, Ukraine. E-mail: office@paton.kiev.ua \\ ${ }^{2}$ BAMTRI. Beijing, China. E-mail: guang@cae.cn
}

\begin{abstract}
Presented are the results of complex of carried out investigations on development of technology for welding by penetration welds of stringer panels of titanium alloy VT20 providing minimum residual stresses and deformations and also high values of their life at cyclic loads. On the full-scale specimens, simulating stringer panels, the penetration welds of T-joints were produced using three methods: electron beam, automatic argon-arc nonconsumable-electrode welding over the layer of activating flux, and automatic argon-arc nonconsumable-electrode welding with immersed arc. To prevent the residual welding stresses and deformations, preliminary elastic deformation of elements being welded was applied. The fatigue tests of all the types of specimens at longitudinal cyclic tension were carried out. The effect of heat treatment, impact mechanical treatment and repair-welding technologies on their fatigue life was also determined. Basing on the results of investigations of full-scale specimens the batches of stringer panels of $1200 \mathrm{~mm}$ length were manufactured and tested. The penetration welds, made by argon arc non-consumable electrode welding over the layer of activating flux using preliminary elastic deformation and high-frequency mechanical peening of welds, provide the higher values of fatigue life of welded stringer panels of high-strength titanium alloy VT20 as compared to electron beam welding and argon arc non-consumable electrode welding with immersed arc. The developed technology can be accepted for industrial production of welded stringer panels of high-strength titanium alloys. 14 Ref., 1 Table, 13 Figures.
\end{abstract}

Key words: thin-sheet welded structures, stringer stiffened panels, T-joints, penetration weld, residual stresses and deformations, preliminary elastic deformation, fatigue strength, high-frequency mechanical peening

Stringer panels of light alloys find ever wider application in aircraft, aerospace engineering, shipbuilding and other fields of industry. The leading aircraft companies pay increased attention to designing of new and updating of existing technologies for manufacture of load-carrying thin-walled panels of high-strength titanium alloys. The characteristic example is application of stringer panels of titanium alloy VT20 of $2.5 \mathrm{~mm}$ thickness and up to $2000 \mathrm{~mm}$ length with argonarc welded-on stiffeners of up to $25 \mathrm{~mm}$ height in the fighters of the Company «Sukhoy». After welding, the panels in a jig of stainless steel are subjected to thermal annealing in electric vacuum furnace for relieving the residual stresses and deformations [1].

In the Langley Research Center (NASA) for manufacture of such structures the method of braze-welding was developed. Using this method, at first Z-shaped stiffeners of titanium alloy are welded-on to the titanium sheet by spots through the interlayer of aluminium brazing alloy, and then the as-assembled structure of the panel is placed to the vacuum chamber where brazing process takes place [1].

The structures of fighter F-14 of titanium alloy are manufactured using EBW providing high properties of a joint and process efficiency [2].

In any case, notwithstanding whether it refers to structures of titanium or other alloys, in thriving of aircraft builders to replace the riveted or milled thin-sheet stiffened structures by the structures with welded-on stiffeners, the technologists encounter the necessity to minimize the influence of such negative factors as residual stresses and deformations, which are present during welding process and greatly decrease the service characteristics of a product, first of all, accuracy and life [3].

To solve the problems of increasing the accuracy and fatigue characteristics of welded thinsheet structures, such methods were developed at the E.O. Paton Electric Welding Institute as preliminary elastic deforming (PED) [4-7] and high-frequency mechanical peening (HFMP) [8], which are nowadays successfully applied for shipbuilding structures of aluminium alloys and steels [9]. It should be noted that unlike other methods of surface plastic deformation, for example, using shot blast treatment, HFMP is dis- 
tinguished by its influence on a narrow fusion zone of 4-7 mm width. It forms compressive residual stresses in the surface layer of fusion zone and decreases concentration of stresses due to smoothing of transition from weld to base metal.

In work [9] the efficiency of PED application to control residual stresses and strains in welding of thin-sheet structures of titanium alloys was experimentally confirmed.

As a rule, in thin-sheet structures the joining of sheet with stiffeners is performed using fusion welding on the side of stiffener. Here, in most cases two-sided fillet welds are used, made by automatic argon-arc welding with tungsten electrode (TIG), EBW or laser welding. The technology of producing penetration welds in the structures, when T-joint is made by one pass only on the side of sheet by its penetration across the thickness and partial penetration of stiffener, is challenging and at the same time more complicated.

However, in arc welding the processes of weld pool formation, heating of near-weld zone and penetration of metal depend greatly on heat transfer and, respectively, heat conductivity of metal. Therefore, in the conventional arc welding the problems of producing the quality penetration welds of relatively large depth, narrow zones of residual tensile stresses and minimum distortions are obvious.

The processes of formation of penetration weld as compared to the butt weld are considerably different. This problem is essentially complicated in use of titanium alloys due to their thermal physical and physical-mechanical properties.

It is known that the main type of metallurgical defects of welded joints of titanium alloys, made both by arc as well as by beam welding methods, are pores. The pore formation in weld metal can be essentially decreased by a careful pre-welding preparation of surfaces of metal in the welding zone. According to the statistic data on defects in welded T-joints of titanium alloy VT20, the most frequent problem occurs with pores of a small size $(0.1-0.4 \mathrm{~mm})$.

The presence of pores in welds scarcely influences the behavior of welded joints at static loads, but considerably decreases life of their operation under the conditions of cyclic loads, sharply decreasing the fatigue strength. In cyclic tensile loads the sources of fracture of titanium alloys mostly arise from the inner weld defects. The longest life is observed in welds with carefully treated smooth transitions from reinforcement to base metal.

It is known that the process of deformation at cyclic loads causes the directed diffusion of hydrogen into the zone, adjacent to pore, with increased stress. The origin of cracks can occur not only from the inner surface of pore but also in the nearest zone. Moreover, the growth of concentration of hydrogen at the surface of developing crack near the pore is by one order higher than at some distance from the pore.

The life of welds is mainly influenced not so significantly by the size of pores, but by their location zone. The pores far from the stress concentrators decrease the life by $2-3$ times, whereas pores in the zone of stress concentration decrease the life by one order [10].

It was noted that application of surface cold working arrests the development of fatigue fracture sources from the defects close to the surface and increases the life of welded joint.

The successful application of welding technology with penetration welds in the panel structures is impossible without development of special measures, which could provide necessary strength and fatigue characteristics of welded joints and structures, low residual welding deformations and stresses, high accuracy of product manufacture alongside with high quality of welds.

The aim of this investigation was the development of technology for manufacture of welded stringer panels of titanium alloy VT20 providing their high accuracy and fatigue characteristics.

Titanium alloy VT20 relates to a pseudo- $\alpha$ alloys with the following content of alloying elements, \%: 5.5-7.0 Al, 1.5-2.5 Zr, 0.5-2.0 Mo, $0.8-2.5 \mathrm{~V}$. The coefficient of stability of $\beta$-phase in this alloy in annealed state depending on the content of alloying elements amounts to $5-7 \%$.

Phase transformations in the alloy during cooling in the process of welding are proceeding according to the martensite kinetics, $\beta \rightarrow \alpha$ transformation is observed. The increase in cooling rate results in refining of $\alpha^{\prime}$-phase formed in weld metal and HAZ, however this does not considerably influence the properties of joints at static tests.

The formed $\alpha^{\prime}$-structure is slightly alloyed by $\beta$-stabilizers, therefore, it is close by its properties to the common $\alpha^{\prime}$-structure with the corresponding alloying. The structure is not changed also in the process of long low-temperature heating. Therefore, annealing for the purposes of stabilizing of structure and hardening postweld heat treatment are not efficient. It is rationally to conduct annealing for relieving residual welding stresses, decreasing concentrations in the site of transition from the base metal to weld.

It should be noted that at the present time at the enterprises producing welded structures of titanium alloys, annealing remains the main 


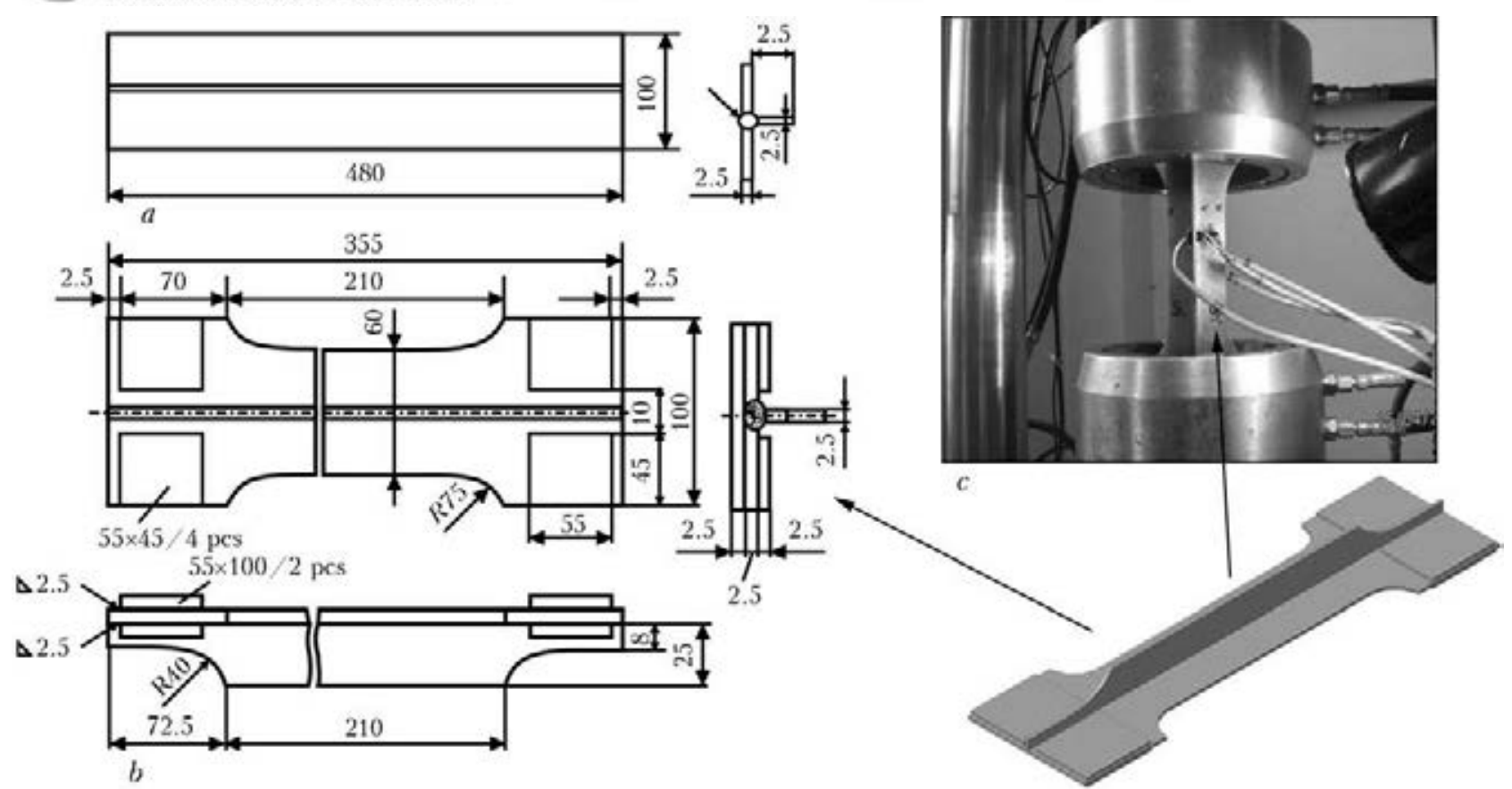

Figure 1. Welded T-specimen of VT20 alloy for the first stage of investigations: $a-$ sketch of specimen; $b-$ sketch of specimen of blade type; $c$ - specimen for fatigue tests clamped in the machine

method used for prevention of residual stresses and deformations. Here, the main disadvantages of this technological process are great energy losses, restricted application due to the sizes of the treated parts and also high material capacity of the rigging, applied for fastening of annealed structures. In this connection, in the present investigations the additional aim was followed, i.e. a search of the alternative for the annealing operation.

The strength properties of weld metal in welding of alloy VT20 are close to the properties of base metal, and slight decrease in ductility is connected with the peculiarity of formation of cast structure. The size of grains in weld metal depends on the energy input introduced in welding. During slow cooling of joint after welding the ductility of cast metal decreases as a result of increase in grains size. At the same time, the high rates of cooling result in decrease of ductility because of formation of fine-acicular $\beta$-structure where $\alpha^{\prime}$-phase is absent [11].

The development of technology of deformation-free welding of stringer panels of alloy VT20 was carried out in two stages. At the first stage, on the experimented T-welded specimens the possible methods of welding-on of stiffener to the sheet by penetration weld in combination with different technological procedures, directed to improvement of accuracy of producing T-joints, were investigated. At the second stage, on the base of mastered technological variants the batch of stiffened panels was manufactured, which were subjected to tests at cyclic tension to confirm the possibility of producing large-size air- craft panels, meeting the operation requirements without heat treatment application.

Welded T-joint specimens and stiffened panels for investigations had geometric parameters corresponding to the parameters of structures applied in the aircraft construction. During performance of tasks of the first stage the welding of T-specimens with one stiffener (Figure 1, $a$ ) was performed, of which specimens of blade type were cut out (Figure 1,b) for fatigue tests.

The design of stiffened panel for the second stage of investigations with four welded-on stringers, and specimen of blade type of it for fatigue tests, are given in Figure 2.

The load-carrying assembly rigging ( $\mathrm{Fi}^{-}$ gure 3) of the first stage of works is designed for manufacture of T-specimens and provides a possibility of preliminary elastic tension of sheet and stiffeners being welded and also simultaneous sheet bending in the transverse direction. It was composed of three functional units: tension of sheet, tension of stiffener, and berth. The unit of tension of T-specimen sheet (see Figure $3, b$ ) was designed according to the principle of a breaking lever, the length of which exceeds the distance between the edges of opposite clamps for the value of required tension of sheet.

The application of the breaking lever in the load-carrying rigging design allowed providing its minimum sizes and weight, due to which it was easily mated without additional resetting with welding equipment for different welding methods. Moreover, the rigging allowed performing nondestructive testing of quality of weld and 

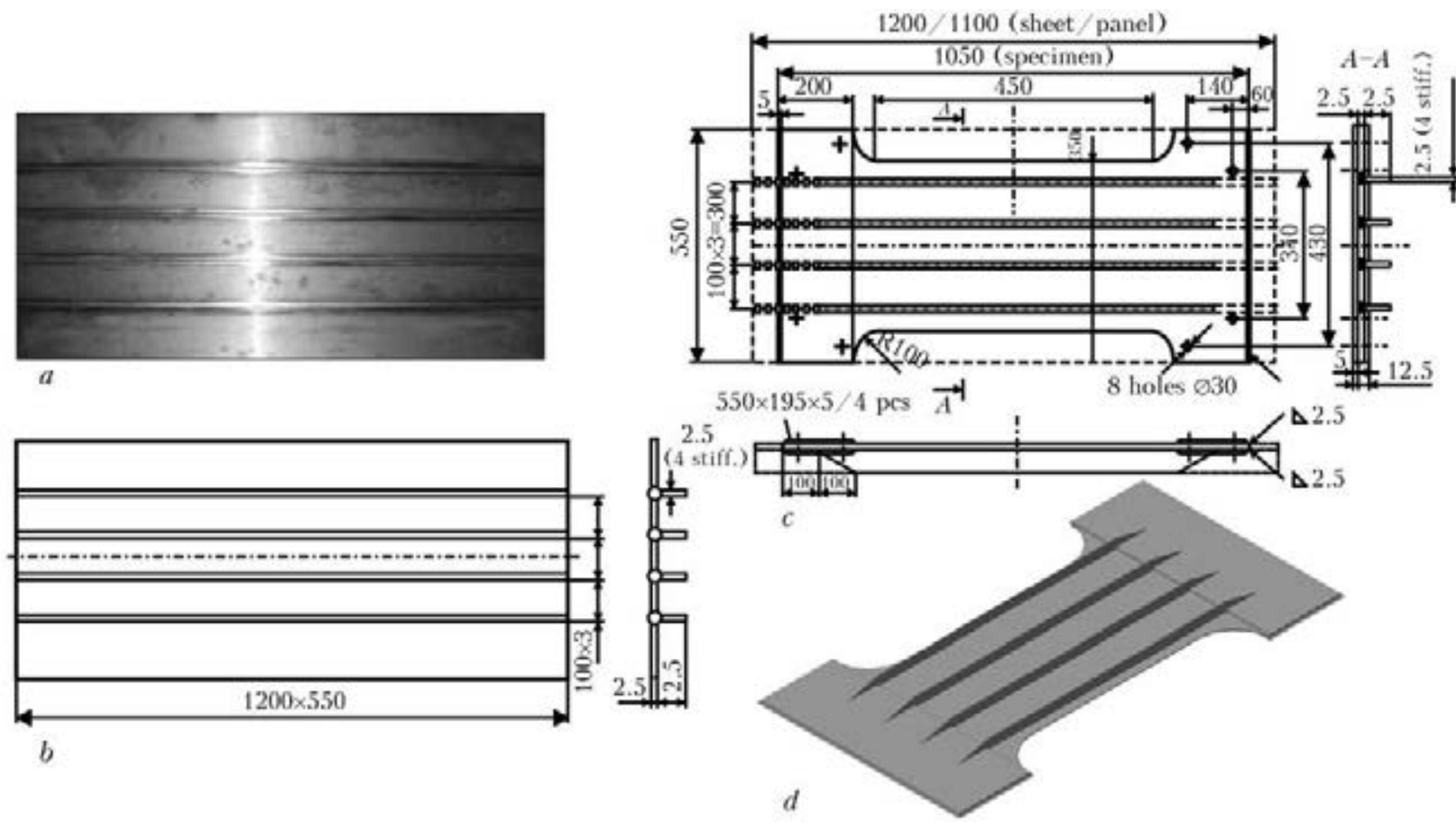

Figure 2. Welded stiffened panel of alloy VT20 for the second stage of investigations: $a-$ general view; $b-$ sketch of panel; $c$ - sketch of specimen of blade type; $d$ - appearance of specimen for fatigue tests

its simultaneous repair at detection of defect directly after welding without disassembly and in tensile state.

In the unit of tension of T-specimen stiffener (see Figure 3,c) the stiffener under tension is located between two traverses, receiving the load, and the tension of specimen is created by a screw jack and transmitted to the stiffener through its clamps.

The unit of berth (Figure 3,d) is manufactured in the form a rigid basement with raising lodgement, which serves as a support for units of tension and has a shape of reverse bending of sheet in the transverse direction, and its longitudinal guides are rectilinear.

In the position for welding the sheet was tightly pressed to the lodgement, and stiffener to the sheet. Moreover, copper water-cooled backings were pressed to sheet and stiffener, which served for formation of fillets of weld root and its gas protection.

Load-carrying welding rigging of the second stage of works, designed for manufacture of stringer panels, is similar and composed of the same units as the rigging for specimens, but with the only difference that there are four units for tension of stiffeners in its composition, which are simultaneously installed below the panel sheet.

The laboratory equipment for argon-arc welding using penetration welds of stiffened specimens and panels under the conditions of PED (Figure 4) was also applied. In welding installation the power source Fronius Magic Ware 3300 was used and also welding head with improved gas protection of arc and cooling weld area, which was moved by a three-coordinate manipulator. The control of welding installation was performed by a programmable controller. The installation included also water cooling and gas cylinder equipment.

At the first stage of investigations, three methods of welding were selected: automatic argonarc nonconsumable-electrode welding over the layer of flux (TIG-F), automatic argon-arc nonconsumable-electrode welding with immersed arc (TIG-I), and EBW. The selection of these methods was determined considering the experience of the PWI works on welding of titanium alloys and need in providing the complete penetration of the sheet, its reliable fusion with the stiffener, uniform formation of fillet transitions on the side of stiffener and also producing the weld reinforcement on the face side without undercuts.

In connection with some physical properties of titanium, certain difficulties in welding occur connected with providing quality formation of penetration weld root on both sides of stiffener with smooth mating of surfaces of stiffener and sheet. It is predetermined, on the one hand, by a high coefficient of surface tension of molten titanium (1.5 times higher than that of aluminium), which hinders a free sagging and formation of solidifying metal on the backing. On the other hand, a low viscosity of molten titanium facilitates the intensification of hydraulic processes in weld pool, that can not only influence 

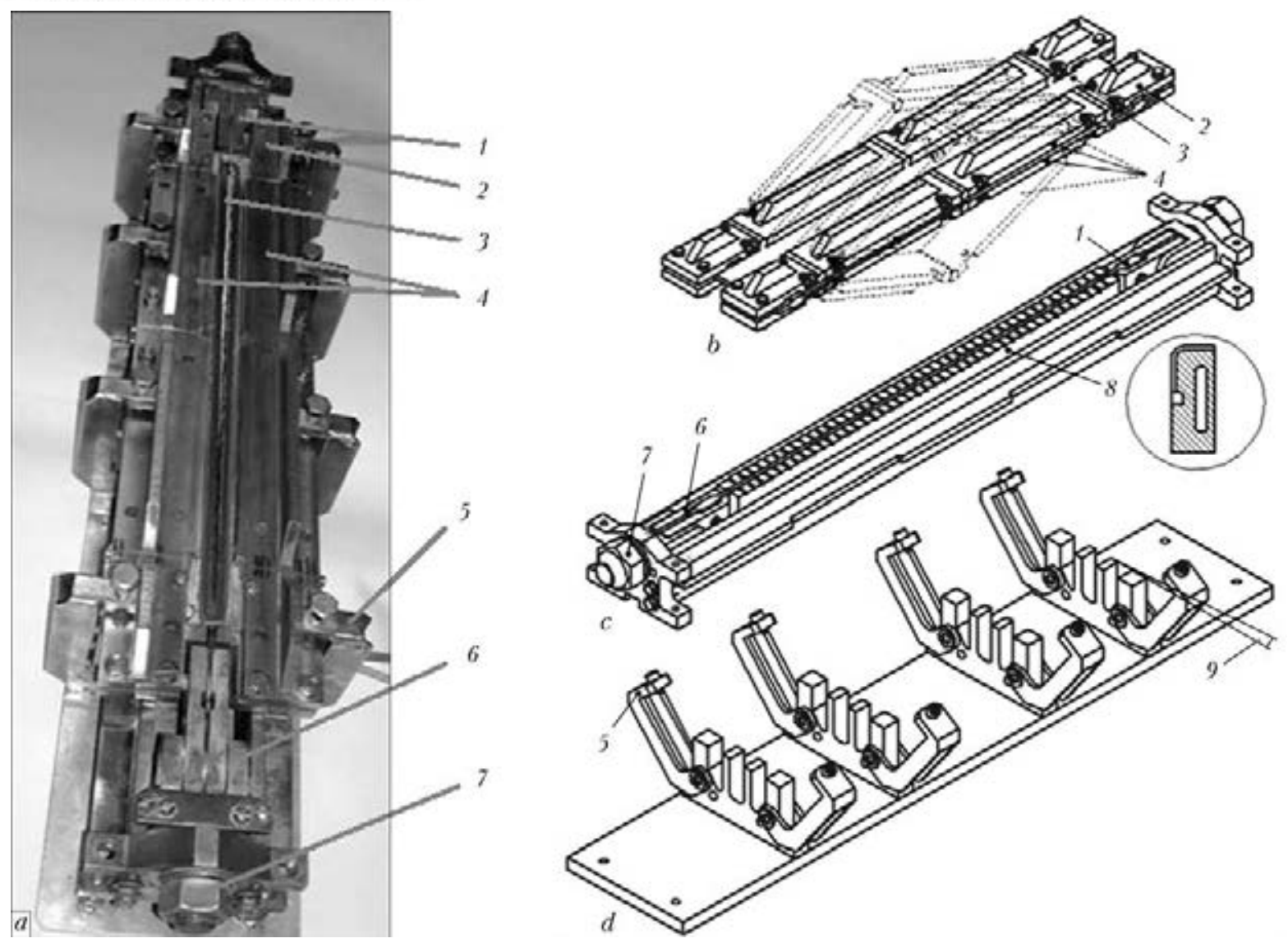

Figure 3. Load-carrying assembly rigging for welding of T-specimens under the conditions of PED: $a-$ general view of rigging with specimen after welding; $b-$ unit of sheet tension; $c-$ unit of stiffener tension; $d-$ unit of birth; 1 , 2 - clamping of stiffener and sheet, respectively; 3 - sheet of T-specimen; 4 - breaking lever; 5 - clamps; 6 - jack rod; 7 - jack nut; $8-$ copper water-cooled backing; $9-$ angle of transverse bending of sheet

the structure of weld and formation of pores in it, but also influence the arc penetrability.

Therefore, in TIG welding of titanium by the surface arc a low coefficient of heat conductivity of titanium and low heat power factor predetermine producing of wide welds with undesirably small coefficient of weld shape (relation of pene-

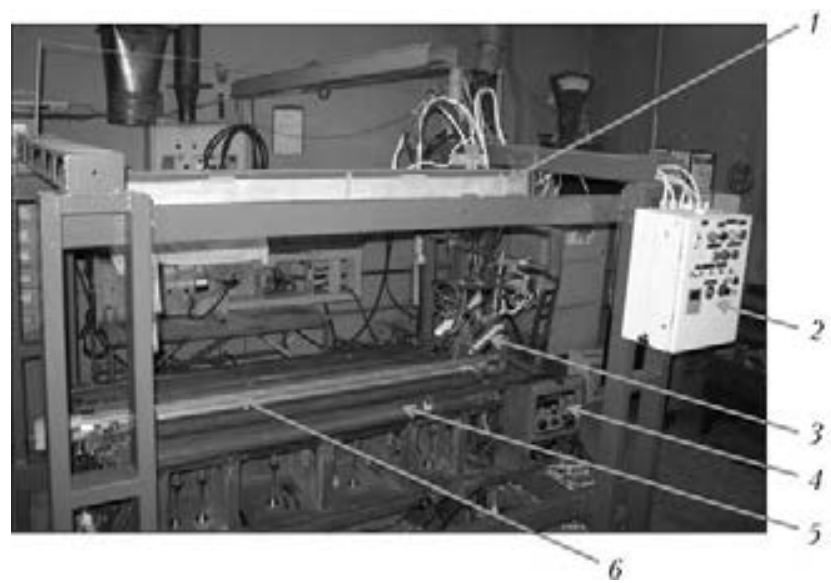

Figure 4. Laboratory equipment for argon-arc welding of stiffened panels under the conditions of PED: 1 - gentry with carriage for movement of welding head; 2 - control unit; 3 - welding head; 4 - power source; 5 - load-carrying assembly stand for PED of parts being welded; $6-$ welded panel tration width to weld depth). To produce the required complete penetration of joint using this method, the considerable increase in welding current and high heat input are required.

The TIG-I welding method is intended to increase the depth of penetration and differs from the method with surface arc by a peculiarity that the arc and also the electrode tip are submerged into the pool lower than the surface of sheet, which considerably complicates the welded joint formation. The conditions of burning of the arc itself and movement of metal in the pool are principally differed from the welding by surface arc. Actually, the whole arc is burning in a conical depression, the walls of which are washed by molten metal flows. It is transferred mostly from the front part of pool to its rear part, where its cooling takes place. In welding by immersed arc the molten metal of weld pool is not sufficiently involved to the total stirring, thus influencing the processes of shape and pores formation.

Using immersion the maximum efficiency of welding arc heat is attained, hydrodynamic processes and heat exchange in weld pool are intensified, however, heat and current loads on the electrode tip are abruptly increased. At decreased values of current or increased speeds the process 
of welding is characterized by frequent short-period short circuits and, respectively, sharp current fluctuations. They cause changes in the shape of electrode due to current erosion of its tip. Due to this the unpredicted jumps of welding process parameters and non-quality formations of welded T-joint occur. The width of weld and depth of penetration are changed. As the arc moves forward, the frequency of short circuits grows and total voltage drops. During this method there is a high probability of getting the unstable result at the same conditions of assembly and welding condition parameters. The process is very sensitive to the temporary welding deformations and it is used to stop because of common short circuiting, arc extinction and «freezing» of electrode at negligible deplanations of sheet, as a rule. Due to that the use of TIG-I welding in manufacture of structures with long welds is restricted.

The EBW method is characterized by comparatively high concentration of energy and, as a rule, is applied for joining of large thicknesses. While producing penetrated $\mathrm{T}$-joints electron beam cuts through the sheet metal quite easily unlike the arc, providing the guaranteed melting of stiffener, which is under the sheet [12]. At the same time, the necessity in formation of radii of fillets (up to $2 \mathrm{~mm}$ ) from below the sheet on both sides of stiffener imposes quite severe restrictions for selection of modes, as this leads to widening the pool on the joint face side. It is difficult to maintain in balance the wide pool on sheet and, as a result, the flaky surface of weld is formed with undercuts. The tendency to burnouts and pores is also high near the root weld. To eliminate the defects in this case the additional smoothing of weld by repeated pass of unfocused beam is necessary.

The analysis of results of selection of EBW mode parameters for T-joints of VT20 alloy with penetration welds shows the following. The better conditions for formation of smooth fillets on the weld bottom are achieved during the modes with deep penetration of beam to the stiffener and high heat inputs, which are close to the process of sheet cutting. However, the better formation of weld surface on the face side is achieved at modes close to the process of smoothing. The selection of optimal mode consists in finding the grounded compromise between these processes.

The method of TIG-F welding is designed for producing welds on titanium alloys of $0.8^{-}$ $6.0 \mathrm{~mm}$ thickness [13]. Before welding a layer of flux is deposited on the surface of parts being welded. The welding is performed in one pass without preparation of edges both with filler wire and also without it. The adding of halogenide fluxes into the welding zone causes constriction of arc, predetermined by physical processes, which occur in the arc column. Here the conditions of welded joint formation are changed in principle and technological capabilities of TIG-F welding are widened as compared to welding using surface arc.

The main advantages of TIG-F welding are increase of penetration depth at negligible decrease of input energy, decrease in width of weld and HAZ, prevention of porosity. Thus, input energy is $1.5-2$ times decreased, width of welds is characterized by the small coefficient of weld shape. Metallurgical treatment of metal of weld pool by a liquid slag almost completely prevents the formation of pores in joint in welding of different titanium alloys. It is connected with the fact that as a result of metallurgical reactions occurred in a weld pool between flux and titanium the chemical binding of hydrogen occurs. Hydrogen, dissolved in weld pool molten metal, is bonded by fluorine to hydride-fluorides remaining in weld metal as microscopic slag inclusions. As the mechanical properties of weld metal are determined by the state of $\alpha^{\prime}$ - and $\beta$-phases and not by interphase interlayers, then TIG-F welding provides sufficiently high level of properties of joints.

Besides, during this method the welding current is increased by $20-25 \%$ above the optimum one, thus leading to the growth of width of reverse formation (by 30-50\%) at negligible increase (by 7-12\%) of weld width. This feature allows efficiently using this method to produce T-welded joints by through penetration of sheet with simultaneous melting of the stiffener.

Carrying out the first stage of investigations on the T-joint specimens with penetration welds the optimal modes of welding process were practiced. The mentioned modes for each of three methods of welding of alloy VT20 are given in the Table.

\begin{tabular}{|c|c|c|c|c|c|c|c|c|c|}
\hline $\begin{array}{c}\text { Method of } \\
\text { welding }\end{array}$ & $\begin{array}{c}\text { Welding } \\
\text { speed, } \\
\mathrm{m} / \mathrm{h}\end{array}$ & $\begin{array}{c}\text { Filler } \\
\text { diameter, } \\
\mathrm{mm}\end{array}$ & Protection & $\begin{array}{c}\text { Beam } \\
\text { current, } \\
\mathrm{mA}\end{array}$ & $\begin{array}{c}\text { Accelerating } \\
\text { voltage, } \\
\mathrm{kV}\end{array}$ & $\begin{array}{c}\text { Focusing } \\
\text { current, } \\
\mathrm{mA}\end{array}$ & $\begin{array}{c}\text { Scanning } \\
\text { amplitude, } \\
\mathrm{mm}\end{array}$ & $\begin{array}{c}\text { Scanning } \\
\text { frequency, } \\
\mathrm{Hz}\end{array}$ \\
\hline EBW & 14 & 1 & Vacuum $\left(10^{-5}\right)$ & 70 & 28 & 80 & 8 & 380 \\
\hline TIG-F & 18 & 1 & Argon & - & - & - & - & - \\
\hline TIG-I & 17 & 1 & Same & - & - & - & - & -195 \\
\hline
\end{tabular}



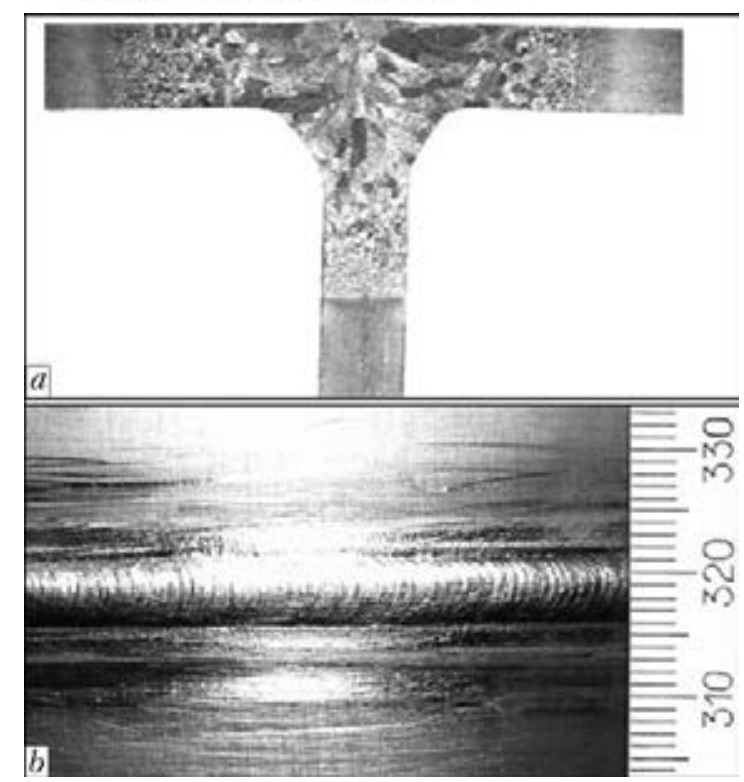

Figure 5. Macrosection ( $a$ ) and appearance $(b)$ of the face side of VT20 welded T-joint of $2.5 \mathrm{~mm}$ thickness of elements (TIG-F welding, flux ANT-25A)

Microstructures of welded joints produced using mentioned methods are quite of the same type. As is seen from Figure 5, microcracks and pores in weld and HAZ metal are absent. It should be noted that the length of HAZ is varied in the ranges of $2.5-3 \mathrm{~mm}$, the weld width amounts to $6-7 \mathrm{~mm}$. In the weld from the fusion zone to the center of welded joint the nonuniaxial grains are solidified, mostly columnar crystallites, elongated to the direction of heat removal. In the central part of joint the crystallites are formed, close to uniaxial shape, which grow together along the axis of weld at the angles of about $60-90^{\circ}$. The grains in weld are uniform by their size.

To strengthen the weld, filler wire VT1-00 (commercial titanium) of $1.0 \mathrm{~mm}$ diameter was used. In the experiments of the first stage the influence of adding of this filler wire to weld pool for decrease of content of alloyed elements in welded joint was investigated. The quantita-

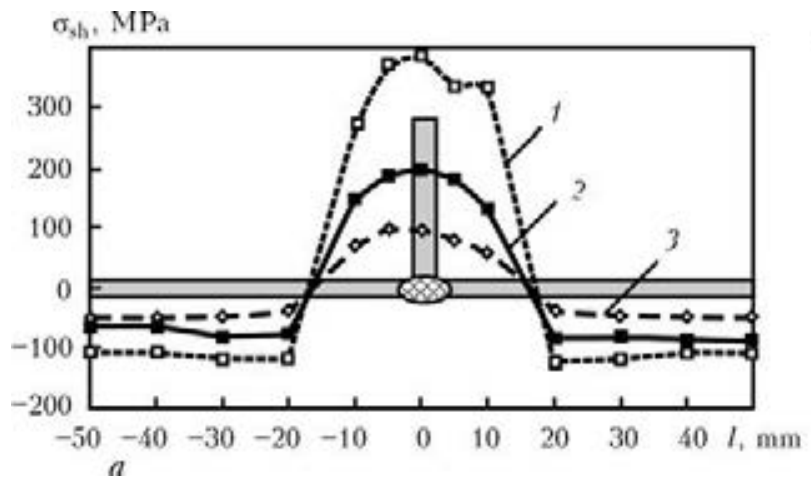

tive evaluation of change in level of weld metal alloying was carried out using X-ray spectral analysis. The content of alloying elements, determined in the single spots, changed in the following ranges, \%: 5.91-6.33 Al; 1.65-1.84 Zr; $0.77-1.24 \mathrm{Mo} ; 1.06-1.17 \mathrm{~V}$, that corresponds to the content of alloying elements in alloy VT20.

To decrease welding stresses and deformations the PED of elements to be welded was applied. The sheet and stiffener were subjected to longitudinal tension at a preset level of stresses. Besides, the sheet was subjected to bending in the transverse direction as regards to angular welding deformations.

To set the optimal parameters of PED, the experiments on determination of dependence of residual stress-strain state of the specimen on the preliminary stresses of tension of sheet and stiffener were determined. It is seen from Figure 6 that residual welding stresses are considerably decreased with increase of preliminary tensile stresses to $0.5 \sigma_{0.2}$. The residual welding deformations of shape changing in welded $\mathrm{T}$-joints are also decreased during increase of initial tensile stresses. Reaching the level of initial stresses $(0.30-0.35) \sigma_{0.2}$ the residual welding distortions almost correspond to the values of deformations of initial sheets.

The reverse transverse bending of sheet is applied to eliminate completely the angular residual deformations. The reverse bending, determined experimentally, amounted to 0.75 of the value of residual angular deformations produced in welding of specimen in a free state.

In T-welded specimens (Figure 7), produced using EBW without application of PED at optimal parameters, the significant torsional deformations are seen and also those of longitudinal and transverse bending, while on the specimens applying PED the mentioned deformations are absent. In welding of specimens using TIG-I and

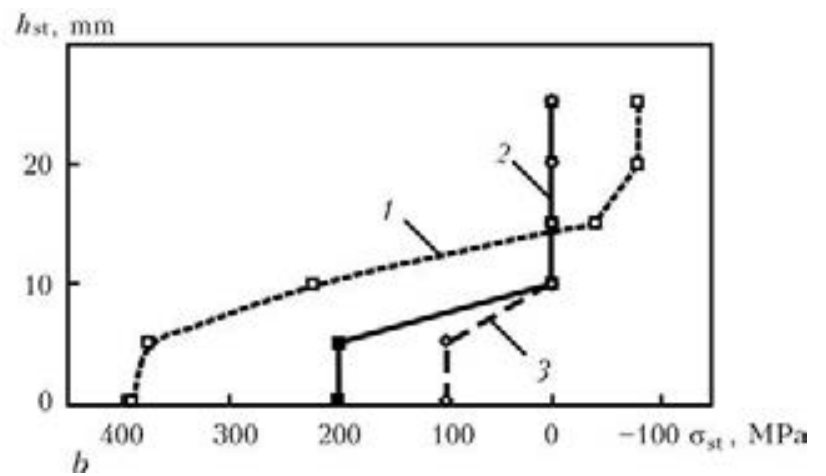

Figure 6. Diagrams of distribution of longitudinal residual stresses in the transverse section of EB-welded T-specimens of alloy VT20 with penetration weld in plate $(a)$ and stiffener $(b): 1-$ welding of specimen in the rigging without tension; $2-$ welding of specimen under the conditions of PED at $\sigma_{\mathrm{sh}}=220$ and $\sigma_{\mathrm{st}}=250 \mathrm{MPa} ; 3-$ welding of specimen under the conditions of PED at $\sigma_{\mathrm{sh}}=\sigma_{\mathrm{st}}=450 \mathrm{MPa}$ 
TIG-F methods under PED conditions and without it, the similar results were obtained.

Five specimens, produced applying three welding technologies, were subjected to PWHT. According to the recommendations accepted during manufacture of elements of welded aircraft structures of titanium alloys, PWHT was carried out in electric furnace in vacuum with automatic control of temperature (Figure 8). To prevent distortions of specimens during treatment the fixing rigging of stainless steel was applied. The applied mode was the following: heating to $650{ }^{\circ} \mathrm{C}$ in vacuum $1.33 \cdot 10^{-1} \mathrm{MPa}$ for $2 \mathrm{~h}$, furnace cooling in vacuum. Then all the specimens were treated by HFMP to increase the fatigue resistance (Figure 9). HFMP of specimens consisted in peening of fusion zones of welded joint both along the sheet as well as along the stiffener using ultrasonic impact tool, where hard-alloy strikers with radius rounding at the ends were used as the working part.

The challenging task in manufacture of thinsheet structures of light alloys is the development of repair-welding technologies and evaluation of their influence on strength and life of welded joints. For T-joints, made with penetration weld, two types of defects are peculiar: absence of smooth transition (fillets) from sheet to stiffener, and also the presence of inner weld defects (pores, inclusions, microcracks). In this connection the evaluation of efficiency of two repair technologies was carried out. To eliminate the first type of defects, smoothing of the fillet using argon-arc nonconsumable-electrode welding was performed, and to eliminate the second one the defects were drilled

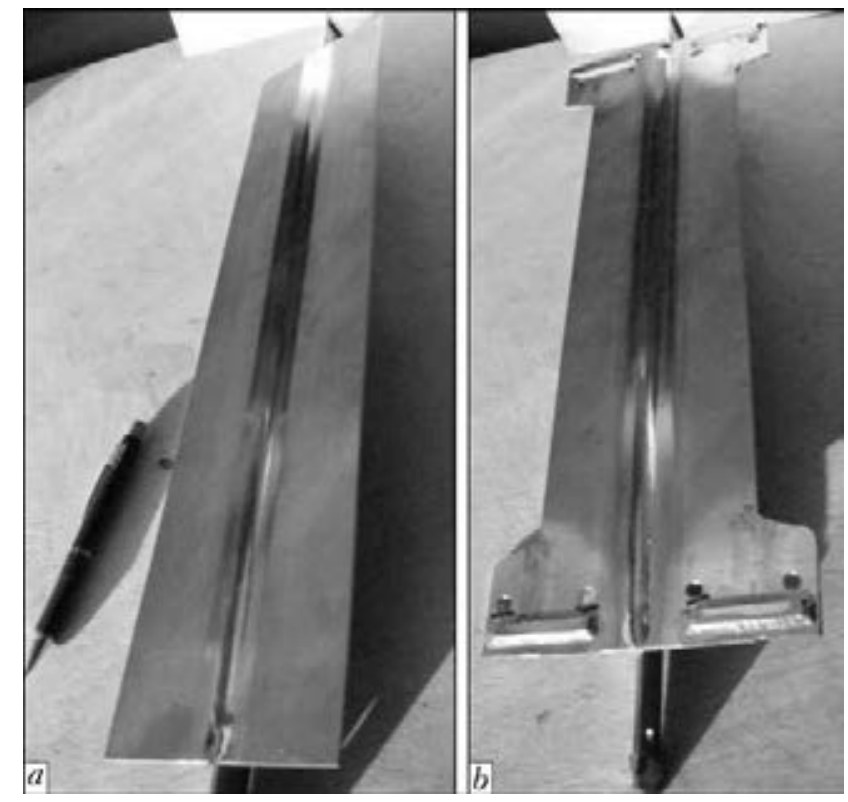

Figure 7. Appearance of T-specimens manufactured using EBW without $(a)$ and with $(b)$ PED of sheet at $\sigma_{\text {sh }}=220$ and $\sigma_{\mathrm{st}}=250 \mathrm{MPa}$

out, at first, on the face part of weld, and then they were filled by argon-arc welding using filler wire VT20 of $2.0 \mathrm{~mm}$ diameter. The repair welding was performed in special rigging providing fixation of the specimen and gas protection of surfaces of sheet and stiffener. After the repair HFMP of welded joints was performed.

For fatigue tests the specimens were fixed in clamps of testing machine URS-20 along the flat areas near the edges (without clamping of stiffener) (see Figure 1, $a$ ) and loaded by longitudinal tensile cyclic load with asymmetry of cycle $R_{\sigma}=$ $=0.1$ at frequency of $7 \mathrm{~Hz}$. The preset tensile

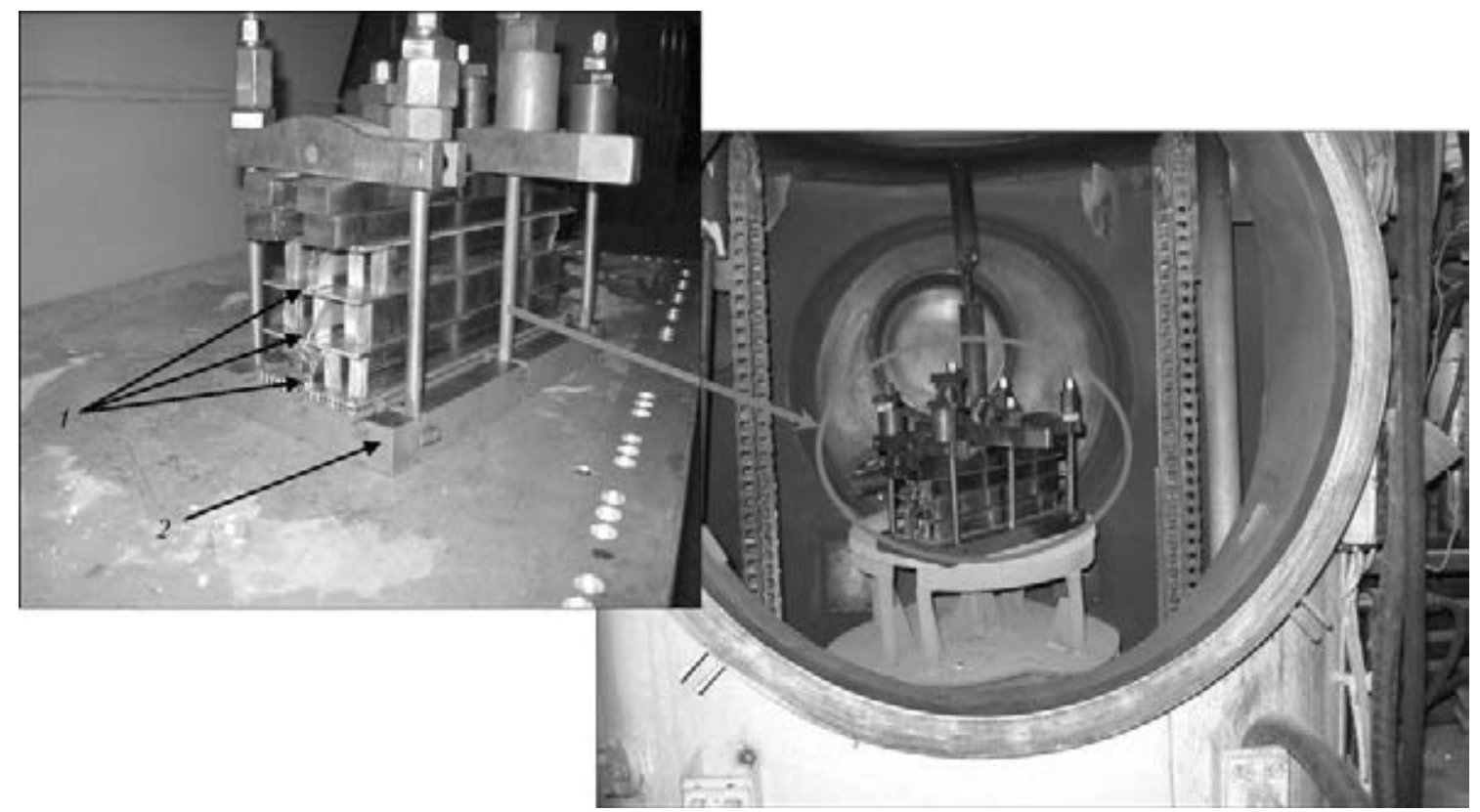

Figure 8. Heat treatment of welded specimens of alloy VT20 in electric vacuum furnace: $1-$ T-specimens; $2-$ rigging for annealing in furnace 


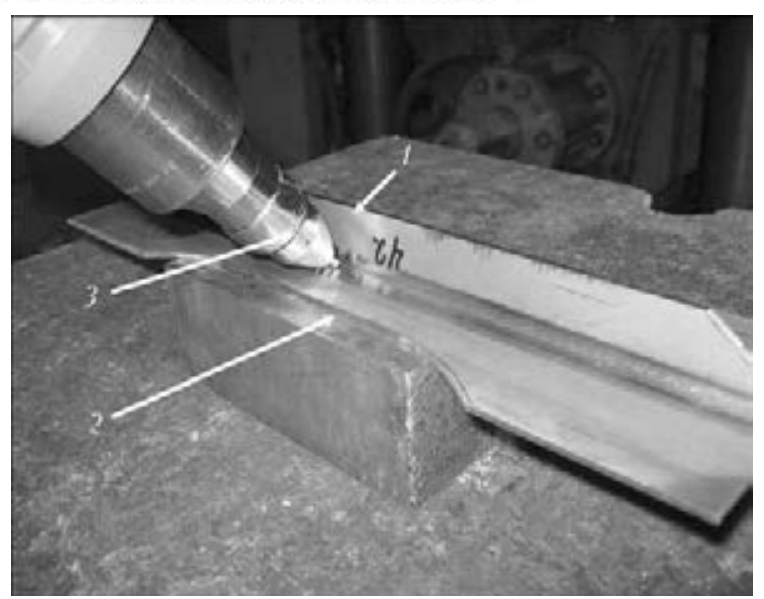

Figure 9. HFMP of specimen of VT20 alloy T-welded joint by hand impact tool: 1 - specimen; $2-$ backing; $3-$ working head of impact tool

force was selected so that the calculation level of maximum stresses of the cycle in specimen sheet part (not considering the stiffener) amounted to $0.5 \sigma_{0.2}$ for alloy VT20. However, at the given scheme of loading the welded-on stiffener was subjected to the certain part of applied loading. As a result, the maximum cycle stresses in T-joint net-section were lower than calculated ones. To determine the real stresses, the strain gauges were used. The measurements performed by them showed that maximum stresses in the middle section of sheet amounted to $350 \mathrm{MPa}$.

The fatigue tests of specimens were carried out until their complete fracture, and corresponding amount of stresses was taken as a criterion for evaluation of investigated variant of welding technology and treatment.

In the summarized diagram in Figure 10 the test results for T-specimens, used in the experiments of the first type, are given. During tests the specimens were mainly fractured in the working sections $60 \mathrm{~mm}$ width. Here the fatigue crack was initiated in the sheet in the transition zone from weld to base metal and further was propagated to both directions until the complete fracture. The microfractographic examinations of the surface of fatigue fractures showed that the character of fracture in the zone of penetration weld was mostly tough-brittle and tough-quasi-brittle.

As the base variants, $\mathrm{T}$-joints produced using one of three welding methods (specimens TIG-I-1, TIG-F-1, EBW-1) without PED were fatigue tested (see Figure 10). As is seen, welding method influences the level of life of tested specimens. The shortest life is observed in EBW and it is increased in TIG-I and TIG-F welding.

PED results in increase of cyclic life of welded specimens (TIG-I-2, TIG-F-2, EBW-2) up to twice as compared to the base variants.
Smoothing of weld legs decreases cyclic life of welded specimens, produced under the conditions of PED, at all the welding methods (specimens TIG-I-3, TIG-F-3, EBW-3).

HFMP by ultrasonic impact tool of welds produced using PED, greatly increases their loadcarrying capacity, especially in TIG-F welding (specimens TIG-I-4, TIG-F-4, EBW-4).

The fatigue properties of welded specimens (TIG-I-5, TIG-F-5, EBW-5) sharply decrease as a result of repair of defect by surface arc on the side of sheet.

The heat-treated specimens (TIG-I-6, TIG-F-6, EBW-6) showed a considerable increase in cyclic life in case of welding over the activating flux. However it should be noted that PWHT is less efficient as compared to mechanical peening of welds using ultrasonic impact tool.

Thus, the fatigue tests of specimens showed that the highest load-carrying capacity of $\mathrm{T}$ welded joints with penetration weld can be obtained in TIG-F and TIG-I welding applying PED and HFMP.

At the second stage the welding of groups of panels was performed using two methods: TIG-I and TIG-F (Figure 11). Technological modes of welding of panels corresponded to the modes of welding of T-specimens. The welding of panels was performed applying PED of sheet and stiffeners at the level $\sigma_{\mathrm{sh}}=\sigma_{\mathrm{st}}=220 \mathrm{MPa}$ and reverse bend with the arrow of bend of $14 \mathrm{~mm}$. Welded joints of all the panels were treated by HFMP using the tool and technology, which were mastered at the first stage of investigations.

It should be noted that as a result of application of PED of sheet and stiffeners the residual shape changes of panels after welding were less than initial bends of sheet plates.

The quality control of welded joints was performed using the method developed at the PWI based on the application of electron shearography [14], which allows operative determination of defect areas of welds without disassembly of loadcarrying rigging and, if necessary, starting the repair immediately. Thus, welding and repair were joined in one technological process, that facilitated the improvement of the quality of panels.

According to the results of quality control on two panels manufactured using TIG-I welding, the defects as a chain of pores of $2 \mathrm{~mm}$ diameter were corrected applying mechanical preparation of the weld. On two panels corresponding to TIG-F welding the repair smoothing of leg area was performed.

To carry out the fatigue tests of welded panels the large-size specimens of blade type with test 


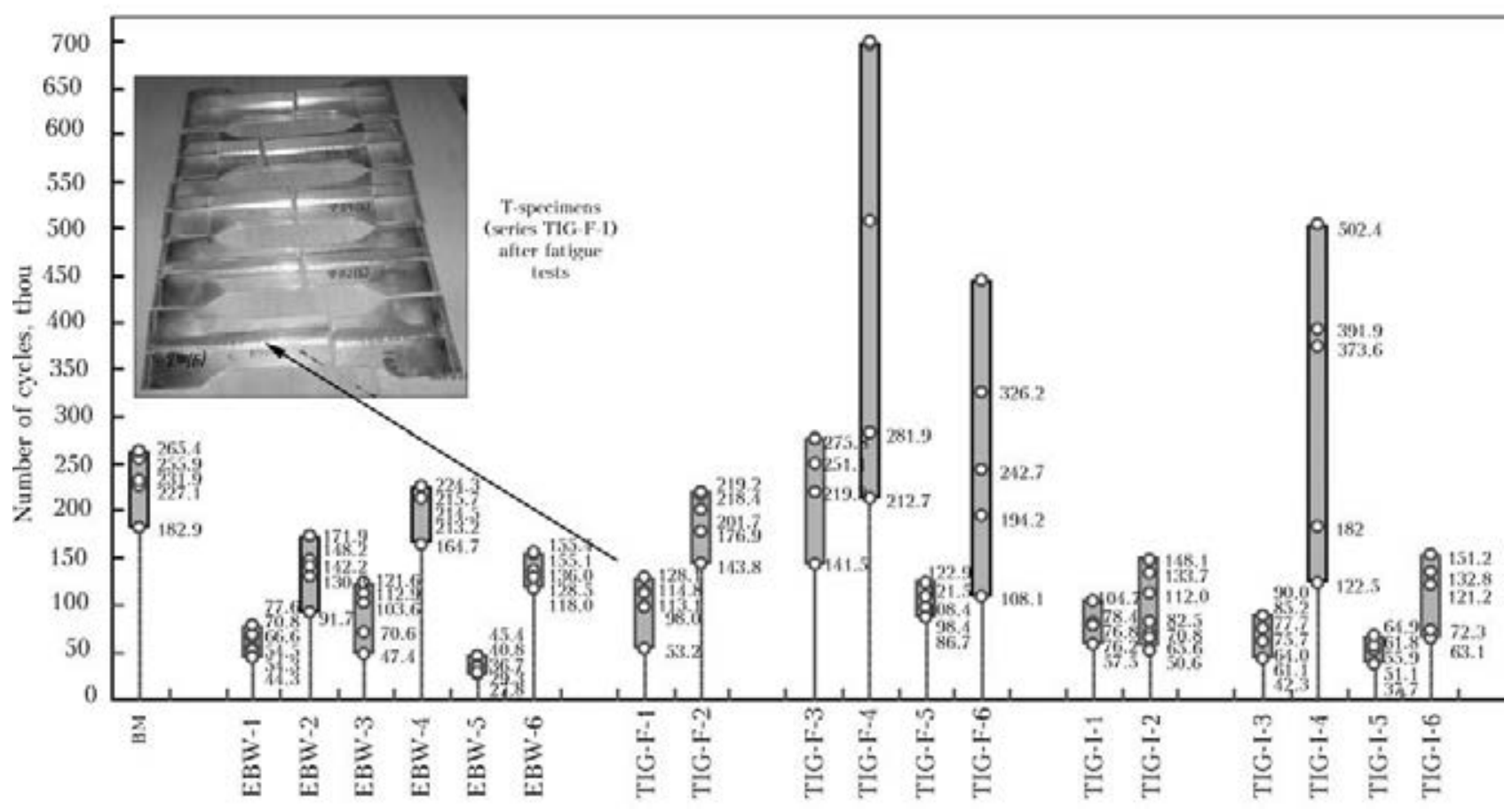

Figure 10. Results of fatigue tests at cyclic longitudinal tension of T-welded specimens of alloy VT20 (indicated using method of welding: 1 - specimens rigidly clamped in the rigging without tension in welding; $2-$ produced applying PED; 3 - with smoothing of weld leg; 4 - treated using ultrasonic impact tool; 5 - with repair of defect atop (or repair simulation); 6 - after heat treatment)

part of $450 \times 350 \times 2.5 \mathrm{~mm}$ and grinded edges were manufactured (see Figure 2,c). The tests were carried out in the modernized universal servohydraulic testing machine HydroPuls-Schenk with maximum tensile force of $100 \mathrm{t}$, the control was performed by 4-channel digital controller MTC Flex Test GT.

For evaluation of the real level of stresses in the test section of the specimen and check up of its correct disposition in the clamps of testing machine the set-up tensometry was carried out for each specimen. For this purpose, strain gauges KF 5 P1-200 connected to tensomeasuring system SIIT-2 were glued in the test part of sheet and stiffeners of specimen in three sections along the length (Figure 12).

In the process of set-up tensometry the panel specimen was loaded stepwise with a pitch of
$50 \mathrm{kN}$ up to maximum tensile loading. At each step of loading the level of stresses was measured according to the strain gauges. Uniformity and maximum stresses on strain gauges were evaluated and, when necessary, maximum test load was corrected to approximate the test conditions of each panel. As a result, maximum test load was set individually for each panel in the limits from 300 to $320 \mathrm{kN}$.

At the fatigue tests the loading of specimens was performed by cyclic loading at the frequency of $0.5 \mathrm{~Hz}$ and the coefficient of cycle asymmetry $R_{\sigma}=0.1$.

The test results of panels manufactured at the second stage of works are presented in Figure 13. As is seen from the diagram, fatigue life of specimens, where the repair of defects of welds is carried
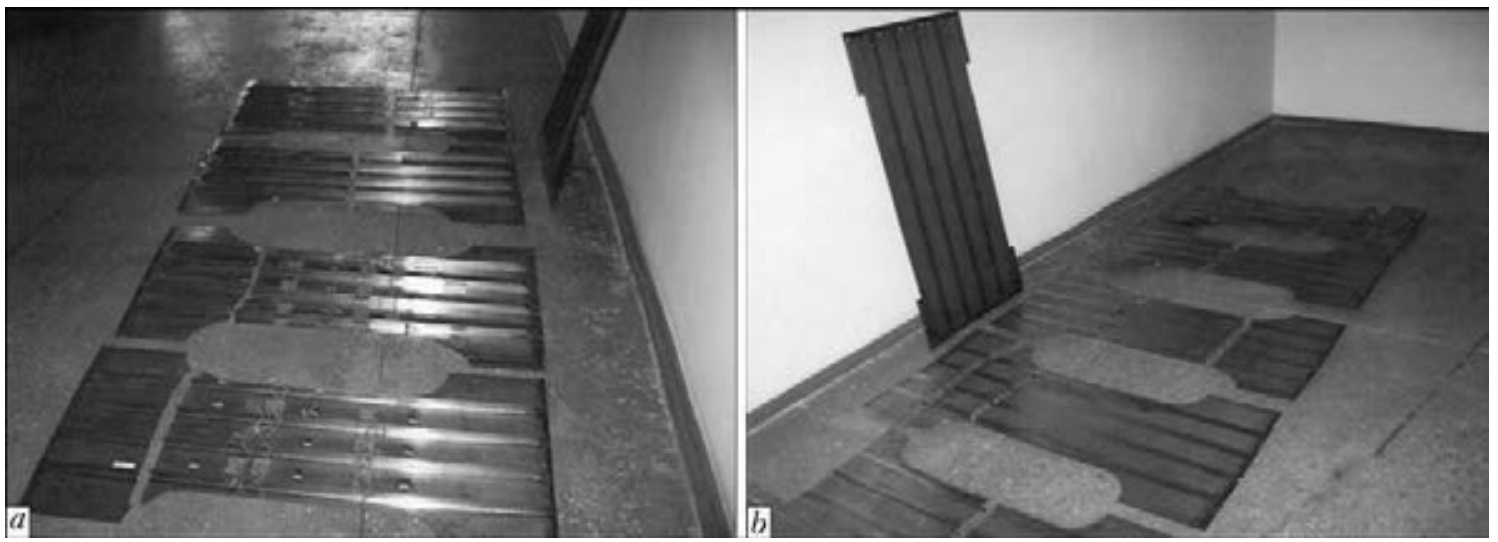

Figure 11. TIG-F- $(a)$ and TIG-I- $(b)$ welded stringer panels of alloy VT20 after fatigue tests 


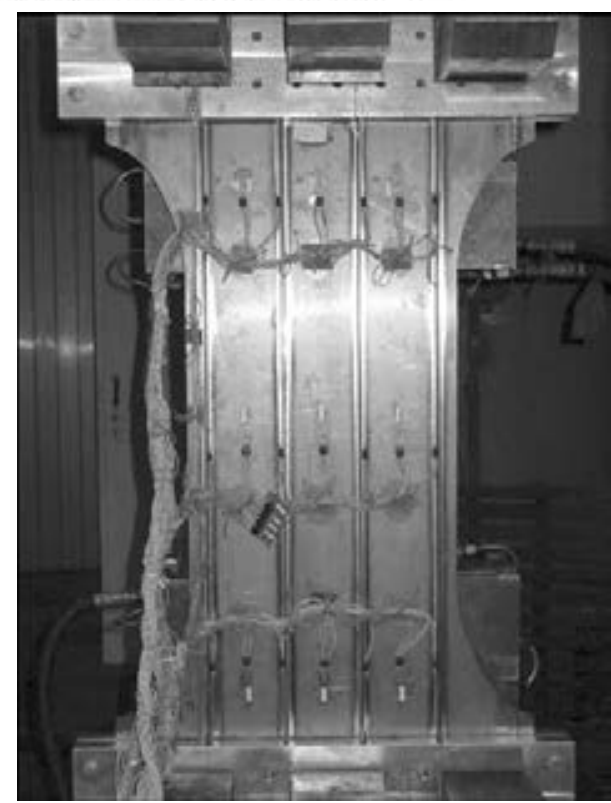

Figure 12. Panel with glued strain gauges installed in the clamps of machine for fatigue tests

out, drops sharply. The higher fatigue life belongs to panels, manufactured applying technology of welding over the layer of activating flux.

The results of the second stage of investigations showed that the technology of argon-arc welding by penetration welds over the layer of activating flux applying PED of the elements being welded and further HFMP of welds can serve as a basis for industrial production of stringer panels of high-strength titanium alloy VT20.

\section{Conclusions}

1. It was established that producing of penetration welds using argon-arc welding by non-consumable electrode over the layer of activating flux, PED and HFMP of welds provides higher values of fatigue life of welded stringer panels of high-strength titanium alloy VT20 as compared to EBW and argon-arc nonconsumableelectrode welding with immersion arc.

2. The application of PED at the level lower than $0.25 \sigma_{0.2}$ in welding of large-size stringer panels of alloy VT20 gives a possibility to eliminate welding distortions and improve the conditions of welding process in automatic mode.

3. The postweld HFMP of welds noticeably increases the fatigue life of structure of titanium alloys.

4. The technology of manufacture of welded stringer panels of alloy VT20 without PWHT was offered.

1. Matvienko, S.V., Astafiev, A.R., Karasyov, I.G. (2003) Welding and related technologies in aircraft construction. Tendencies of development. Svarka $v$ Sibiri, 2, 36-40.

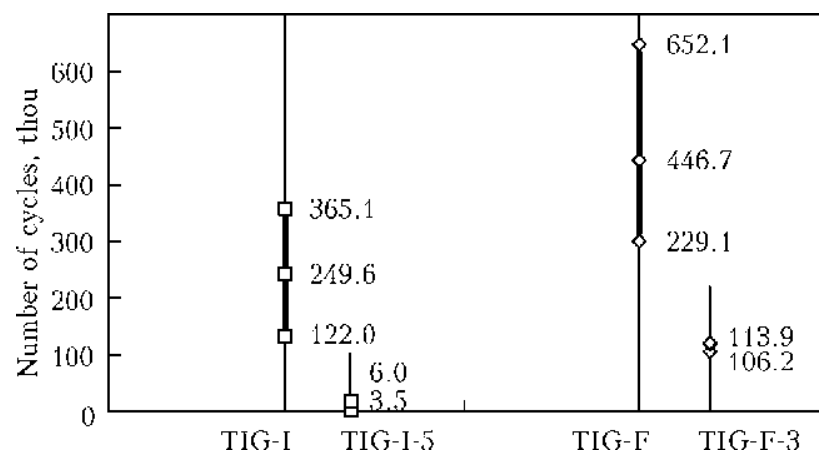

Figure 13. Results of fatigue tests at cyclic longitudinal tension of alloy VT20 welded panels (designated using method of welding: TIG-I-5, TIG-F-3 - panels with repair of weld defect, respectively, with preparation of its face side and smoothing of leg from the weld back side)

2. Robert, W., Messler, J.R. (2007) The greatest story never told: EB welding on the F-14. Welding J., May, 41-47.

3. Bratukhin, A.G., Dmitriev, O.N., Kovalkov, Yu.A. (1997) Stamping, welding, brazing and heat treatment of titanium and its alloys in aircraft construction. Moscow: Mashinostroenie.

4. Paton, B.E. (1992) Advanced trends in improvement of welded structures. In: Welding and Surf. Rev., Vol. 2., 1-8. Amsterdam: Harwood Acad. Publ.

5. Paton, B.E., Utkin, V.F., Lobanov, L.M. et al. (1989) Fabrication of welded large-sized panels from high-strength aluminium alloys. Avtomatich. Svarka, 10, 37-45

6. Lobanov, L.M., Pavlovsky, V.I., Lysak, V.V. (1987) Elastische Vorspannung beim Schweissen von Duennblechen aus Aluminiumlegierungen. Schweisstechnik, 10, 443, 447-449.

7. Lobanov, L.M., Pavlovsky, V.I., Pivtorak, V.A. (1992) Optical methods of studying and means of controlling welding strains and stresses. In: Welding and Surf. Rev. Amsterdam: Harwood Acad. Publ.

8. Lobanov, L.M., Kirian, V.I., Knysh, V.V. et al. (2006) Improvement of fatigue resistance of welded joints in metal structures by high-frequency mechanical peening (Review). The Paton Welding J., 9, 2-8.

9. Stanhope, F., Hasellhurs, R.H. (1972) Welding airframe structures in titanium alloys using tensile loading as a means of overcoming distortion. In: Proc. of Int. Conf. on Welding and Fabrication of Non-Ferrous Metals (Eastbourne, 1972), Vol. 1, 72-82.

10. Muraviov, V.I. (1986) Specifics of fabrication and quality evaluation of large-sized thin welded structures of VT20 alloy. Avtomatich. Svarka, 8, 15-18.

11. Zamkov, V.N., Prilutsky, V.P., Petrichenko, I.I. et al. (2001) Effect of the method of fusion welding on properties of welded joints in alloy $\mathrm{Ti}-6 \mathrm{Al}-4 \mathrm{~V}$. The Paton Welding J., 4, 2-6.

12. Savitsky, V.A., Shevelev, A.D., Zamkov, V.N. et al. (1989) Electron beam welding of stiffened panel elements in VT20 titanium alloy. Avtomatich. Svarka, 4, 55-57.

13. Paton, B.E., Zamkov, V.N., Prilutsky, V.P. et al. (2000) Contraction of the welding arc caused by the flux in tungsten-electrode argon-arc welding. The $\mathrm{Pa}^{-}$ ton Welding J., 1, 5-11.

14. Lobanov, L.M., Pivtorak, V.A., Savitskaya, E.M. et al. (2011) In-process quality control of welded panels of alloy VT20 using method of electron shearography. Ibid., 11, 22-27. 